\title{
Effect of Constant Light on Parturition and Postpartum Reproduction in the Rat
}

\author{
DAVID L. ROWLAND $* \dagger^{\prime}$ AND PIETER VAN DER SCHOOT $\dagger$ \\ *Department of Psychology, Valparaiso University, Valparaiso IN, 46383 USA, and †Department of Endocrinology \\ and Reproduction, Erasmus University Rotterdam, Faculty of Medicine and Health Sciences, \\ 3000 DR Rotterdam, The Netherlands, E-Mail: drowland@exodus.valpo.edu
}

\author{
Received 2 September 1994
}

\begin{abstract}
ROWLAND, D. L. AND P. VAN DER SCHOOT. Effect of constant light on parturition and postpartum reproduction in the rat. PHYSIOL BEHAV 58(3) 567-572, 1995. - Light-dark (LD) cyclicity contributes to a number of reproductive events in the rat, including estrus cyclicity, and the timing of parturition and postpartum estrus. Constant light (LL) disrupts the female's cyclicity, and fertility is typically diminished. To ascertain whether constant light similarly diminishes the fertility of postpartum females, LL and LD animals were compared over three successive pregnancies on several reproductive measures including parturition, postpartum estrus and spontaneous ovulation, the timing of estrus relative to parturition, and the number, body weights, and viability of offspring. While the $24 \mathrm{~h}$ pattern of parturition differed for LL and LD groups, postpartum estrus and ovulation occurred reliably in both groups. The LD group showed greater variation in the birth-estrus interval, the result of a delayed estrus in those females giving birth late in the light phase. The likelihood of spontaneous ovulation and overall successful reproduction was high for both groups. Thus, unlike the cycling female, the fertility of the postpartum female is relatively unaffected by constant light. As such, these findings suggest that LD cyclicity is not critical for postpartum ovulation and estrus.
\end{abstract}

Ovulation Estrus Photoperiodism Birth Postpartum Receptivity Female Sexual behavior

LIGHT-DARK (LD) cyclicity is known to exert a strong influence on a wide range of reproductive processes in the female laboratory rat. For a cycling female on a standard lighting regime, both the preovulatory surge of luteinizing hormone and ovulation are synchronized with the LD cycle. The former typically begins between 1400 and $1500 \mathrm{~h}$ (LD 14:10, L on at 0500), the latter during the early hours of the morning (dark phase) of estrus $(11,33)$. Estrous behavior is also influenced by LD cyclicity, commencing in the late part of the light phase of proestrus and continuing for $7 \mathrm{~h}$ or more into the dark phase $(20,30)$. The critical role of light cyclicity in this process is demonstrated by the finding that the introduction of constant light eliminates ovarian cyclicity within 20-50 days (12) and produces a decline in fertility $(5,6)$. Thus, despite the continuation of an endogenous circadian rhythm, the female rat ceases to ovulate spontaneously (27) and shows tonically elevated levels of estrogen (state of constant estrus). This elevated estrogen reportedly increases the proportion of time that the female shows receptive behavior toward a male $(6,18)$; and mating under these conditions may effectively trigger ovulation such that the female becomes a reflex ovulator (e.g., 6,32). However, the incidence of pregnancy and viability of the offspring from matings occurring during lightinduced constant estrus are greatly reduced in comparison with matings during the estrous cycle (5). This condition may resemble that of the female rabbit, a reflex ovulating species charac- terized by high prenatal mortality from preimplantation loss of ova as well as loss of embryos (1).

The diurnal rhythm of light and darkness also plays a role in determining the time of parturition in the rat. Numerous reports have demonstrated a strong bias toward birthing in the light phase of the photoperiod $(22,25)$. Furthermore, altering day length or introducing constant light has a significant effect on the distribution of births over the $24 \mathrm{~h}$. cycle $(3,4,13,22,24,26)$.

Within the immediate postpartum period, ovulation and estrus are likewise influenced by the LD cycle. These events depend partly on the time of birth, which itself is affected by LD cyclicity. Thus, most reports indicate that a specified amount of time after birth must elapse before postpartum estrus and ovulation occur. The result is that postpartum estrus, occurring some $6-12 \mathrm{~h}$ after daytime birth, is typically observed during the dark phase $(8,14,15,19,33)$. But the LD cycle also appears to affect postpartum ovulation and estrus through a second mechanism. Specifically, births that occur late in the light phase often result in a further delay in postpartum ovulation and heat of 6-12 h (14). Such findings have led to the suggestion that the occurrence of postpartum heat depends on two separate mechanisms. One is the time interval since parturition, with its beginning possibly being activated by the events surrounding the labor process (e.g., cervical stimulation, 14). The second mechanism is a circadian process entrained to the LD cycle which signals time of day, and thus is responsible for coordinating endocrine events nec-

\footnotetext{
' To whom requests for reprints should be addressed.
} 
essary for the postpartum preovulatory LH surge and estrous behavior $(14,15,19)$. However, the precise way in which these mechanisms interact, and the relative importance of each, have yet to be fully understood.

The present study was designed to investigate further the relationships among parturition, postpartum estrus and ovulation, and LD cyclicity. Three questions were addressed. (i) What role does the LD cycle play in the occurrence and timing of parturition and postpartum estrus? (ii) Does long-term exposure to constant light (LL) reduce the female's capacity for successful reproduction during the postpartum by interfering with estrus/ovulation or by reducing offspring viability, as typically occurs in the lightinduced constant estrus female? (iii) Does long-term exposure to constant light eliminate spontaneous ovulation during postpartum estrus, as in the light-induced constant estrus female?

\section{Subjects and Groups}

METHOD

Forty-nine female rats, obtained from the local colony of the RxU Wistar strain and maintained on a 14:10 LD schedule (lights on at 0500 ), were housed individually with food and water ad lib under constant temperature $\left(21 \pm 1^{\circ} \mathrm{C}\right)$ in an isosexual room $(6$ $\times 4 \mathrm{~m}$ ) with standard fluorescent overhead lighting. Cages were positioned such that each received direct photic stimulation from the light source.

Approximately half the females $(n=26)$ were nulliparous $(2-3 \mathrm{mos})$, the rest were primiparous $(n=23)(4-5 \mathrm{mos})$. Beginning at 1700 , females were moved to a separate room for mating with an experienced male and remained there overnight. If sperm was found in the vaginal tract the next morning, the female was returned to her home cage and this day was designated Day 1 of gestation. If no sperm was found, the procedure was repeated nightly until a positive vaginal smear occurred. Using this procedure, mating and male ejaculation occurred after the onset of the LH surge but prior to ovulation; as such, the timing of fertilization was determined by the ovulatory sequence.

To facilitate implantation during the first pregnancy, females were maintained on an LD schedule until Day 6 of gestation. On this day, the first group (LD), consisting of females drawn equally from nulliparous and primiparous groups, continued on the light regimen described above (LD 14:10). The remaining females forming the second group (LL) were placed in a similar room under a constant light regimen (LL 24:0).

\section{Procedure}

For an overview of the experimental procedure, see Table 1. Beginning on Day 21 of gestation, females were visually checked every 60-90 min for signs of labor or birth. The appearance of the first pup was considered the time of onset of parturition. If no part of the parturitional process was observed directly, birth time was estimated as the midpoint between the two nearest observations. At birth, pups were counted and weighed, and large litters were culled to 10 . Small litters were adjusted upward to 4 from litters of the same day having more than 10 pups.

Beginning 3-4 h after parturition, females underwent tests for sexual receptivity (defined by full lordotic posture in response to an attempted mount by a male) with a sexually experienced male every 60-90 min so that the interval between birth and the onset of postpartum estrus could be estimated. If the male did not attempt to mount within $5 \mathrm{~min}$ of the onset of testing, another male was substituted. For nonreceptive females, testing continued for approximately $15-20 \mathrm{~min}$ (typically 5-8 attempted mounts); she was then returned to her home cage until the next
TABLE 1

EXPERIMENTAL DESIGN

\begin{tabular}{|c|c|}
\hline $\begin{array}{l}\text { No. of Days After } \\
\text { Experiment Onset }\end{array}$ & Procedure \\
\hline $1-5$ & first mating \\
\hline $6-10$ & $\begin{array}{l}50 \% \text { moved to constant light (day } 6 \\
\text { postimpregnation for each female) }\end{array}$ \\
\hline $23-28$ & $\begin{array}{l}\text { first parturition } \\
\text { first postpartum estrus and second mating } \\
\text { litters adjusted } 4-10\end{array}$ \\
\hline $\begin{array}{c}32 \\
49-51\end{array}$ & $\begin{array}{l}\text { litters removed to synchronize implantation } \\
\text { second parturition } \\
\text { second postpartum estrus and third mating } \\
\text { litters adjusted } 4-10\end{array}$ \\
\hline $\begin{array}{c}56 \\
73-75 \\
79-87\end{array}$ & $\begin{array}{l}\text { litters removed to synchronize implantation } \\
\text { third parturition } \\
\text { autopsy and inspection of ovaries }\end{array}$ \\
\hline
\end{tabular}

test $1 \mathrm{~h}$ later. For receptive females, copulation continued until the second ejaculation was noted, at which time the female was returned to her home cage.

Between the 4th and 9th day postpartum, pups were removed from the dam at 0600 . The removal of pups was done simultaneously (the same calendar day) for all dams, independent of their day of parturition, to synchronize blastocyst implantation for the second gestation (see 35). Females were allowed to carry their new litters to term when all the measures were repeated.

Between Day 5-7 after the second parturition, pups were again removed at 0600 on the same calendar day to synchronize implantation for the third gestation. For the third parturition, measurements were limited to the presence or absence of birth, pup weights, and litter size. During this postpartum, determination of spontaneous ovulation was made. Females were not placed with an active male during postpartum estrus, since such stimulation may be adequate to induce ovulation (31).

Spontaneous ovulation was assessed in an indirect way to minimize chances of false negative results which could emerge from two sources: examination of the animals prior to the ovulatory moment or examination too long after ovulation so that eggs had disappeared from the oviducts. As the corpora lutea of pregnancy gradually regress and diminish in size while those formed after postpartum ovulation develop in size, days 6-14 after parturition offer the unequivocal possibility for establishing the presence of corpora lutea which were derived from postpartum ovulation and which became activated through the sucklinginduced rise in prolactin secretion. LL dams $(n=18)$ were examined for corpora lutea 10-14 days postpartum. As a control, 8 LD dams were examined 6-14 days following the third parturition.

\section{Data Analyses}

No significant differences were found between nulliparous and primiparous females on measures analyzed in this study; therefore these groups were combined for all further analyses. Analysis on most variables was carried out using a two-way ANOVA, with GROUP (LL vs. LD) as a between group factor, and BIRTH (1st, 2nd, or 3rd birth observed in this experiment) as a repeated measures factor. Posthoc analysis utilized the Newman-Keuls test. For several analyses, comparison across BIRTH was not meaningful (e.g., gestation length) and therefore $t$-tests were used to compare groups. When data showed dissimilar var- 
iances across GROUP or BIRTH variables (determined by Fmax), nonparametric analysis (e.g., Mann-Whitney or Wilcoxon matched pairs) was chosen. For analysis of categorical variables or proportions, chi square or the McNemar test for dependent samples was used; or the test for significance of difference in proportions (7) between groups or across parturitions was used.

\section{RESULTS}

\section{Length of Gestation and Time of Birth}

Gestation length. For the first birth, gestation length was shorter for LL females than for LD females [526.2 vs. $534.0 \mathrm{~h}$; $t(47)=2.97, p=.005]$. For the second birth, length of gestation, measured as the interval from removal of pups during the postpartum (to induce synchronized implantation) to the appearance of the first pup, did not differ between LL and LD groups [448.5 vs. $450.3 \mathrm{~h} ; t(34)=.30, p=.77$ ].

Day of birth. For the LL group, $92 \%$ of first births occurred on Day 22 (the rest on Day 23); for the LD group, $96 \%$ of first births occurred on Day 22 (the rest on Day 23). For the second birth of the LL group, $14 \%$ gave birth on the 17 th day after pup removal, $18 \%$ on the 18 th day, and $68 \%$ on the 19 th day. For the LD group, $7 \%$ gave birth on the 16 th day, $14 \%$ on the 18 th day, and $78 \%$ on the 19 th day.

Patterns of parturition within the $24 \mathrm{~h}$ cycle. Distribution of births over the $24 \mathrm{~h}$ period are illustrated in Fig. 1 and Fig. 2. To test for specific birth patterns, the $24 \mathrm{~h}$ day was divided into four 6-h intervals. For the LD group, two of these intervals represented light (L) periods, and two represented mainly dark (D) periods: (1) 0000 to 0600 (D); 0600 to 1200 (L); (3) 1200 to 1800 (L); and (4) 1800 to 2400 (D).

LL females showed different patterns for the first and second parturitions $\left[\mathrm{X}^{2}(3)=13.03, p<.001\right]$. Specifically, for the first parturition for LL subjects, $100 \%$ of births occurred between 1530 and 0115 , an $8 \mathrm{~h}$ time frame. In contrast, second births for LL females were distributed evenly throughout the $24 \mathrm{~h}$ period. LD females showed a pattern of parturition that did not differ over first and second births $\left[\mathrm{X}^{2}(3)=1.51, p>.05\right)$, but one that was different from LL females $\left[\mathrm{X}^{2}(3)=36.9, p<.001\right]$. With two exceptions all births from this group occurred during the light phase, between 0500 and 1900 . Within the $14 \mathrm{~h}$ light phase, the greater percent $(69 \%)$ of births occurred during the first $7 \mathrm{~h}$ pe$\operatorname{riod}(z=2.65 ; p=.008)$.

Interval between parturition and postpartum estrus. The percent of females displaying postpartum estrous behavior following each birth, as well as the time interval between the onset of parturition and the onset of postpartum estrus, are provided in Table 2. No differences in the proportion of females showing postpartum estrus were found between LL and LD females after either first or second births $(z \leq .50 ; p \geq .69)$. Because variances for the time interval between parturition and postpartum estrus lacked homogeneity across groups $\left[F_{\max }(4,20)=5.6 ; p<.01\right]$,

\section{Birth-Postpartum Estrus Interval}
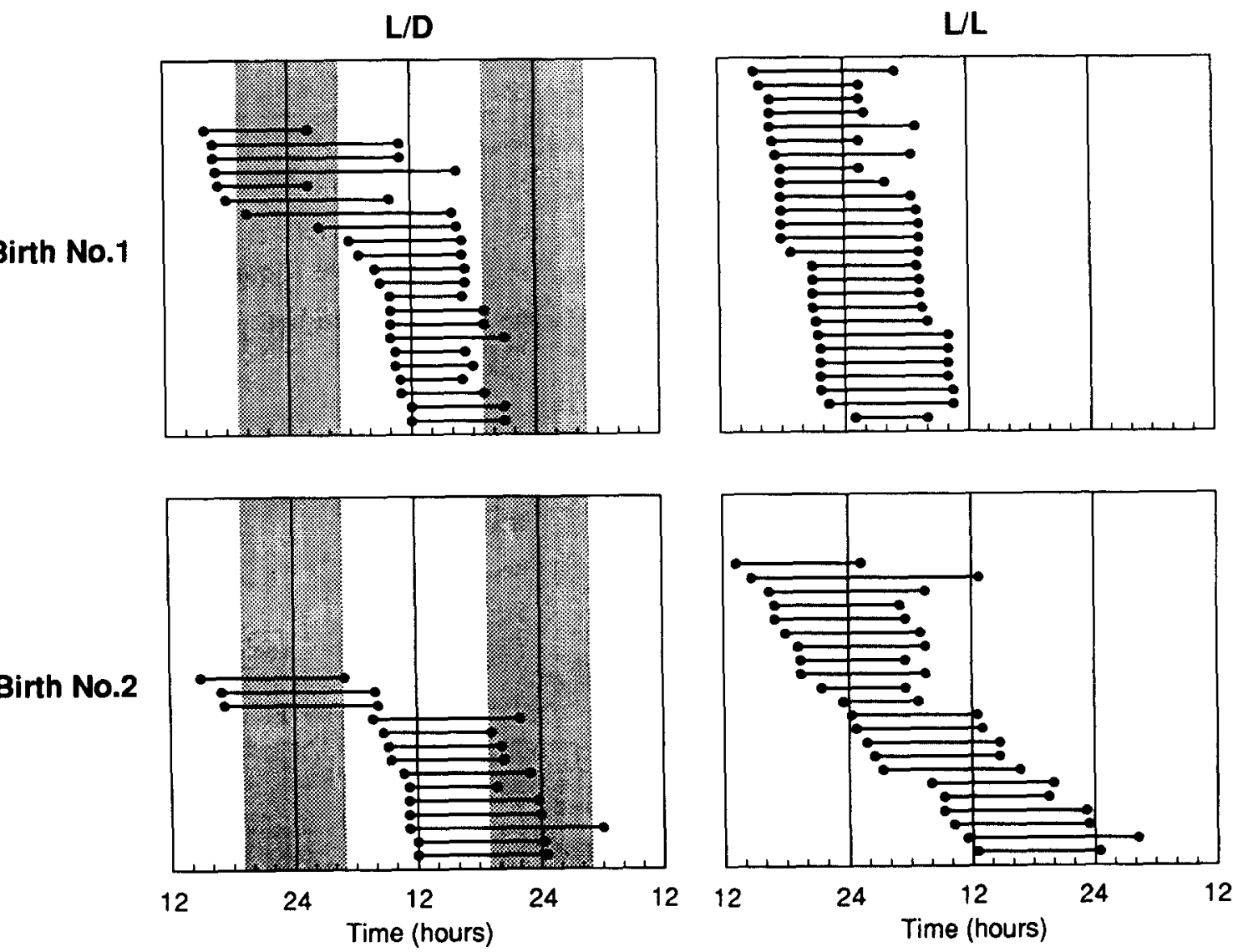

FIG. 1. Parturition-to-postpartum estrus interval for first and second births in females under LD or LL lighting. Shaded area represents lights off. 


\section{Birth-Postpartum Estrus Interval}
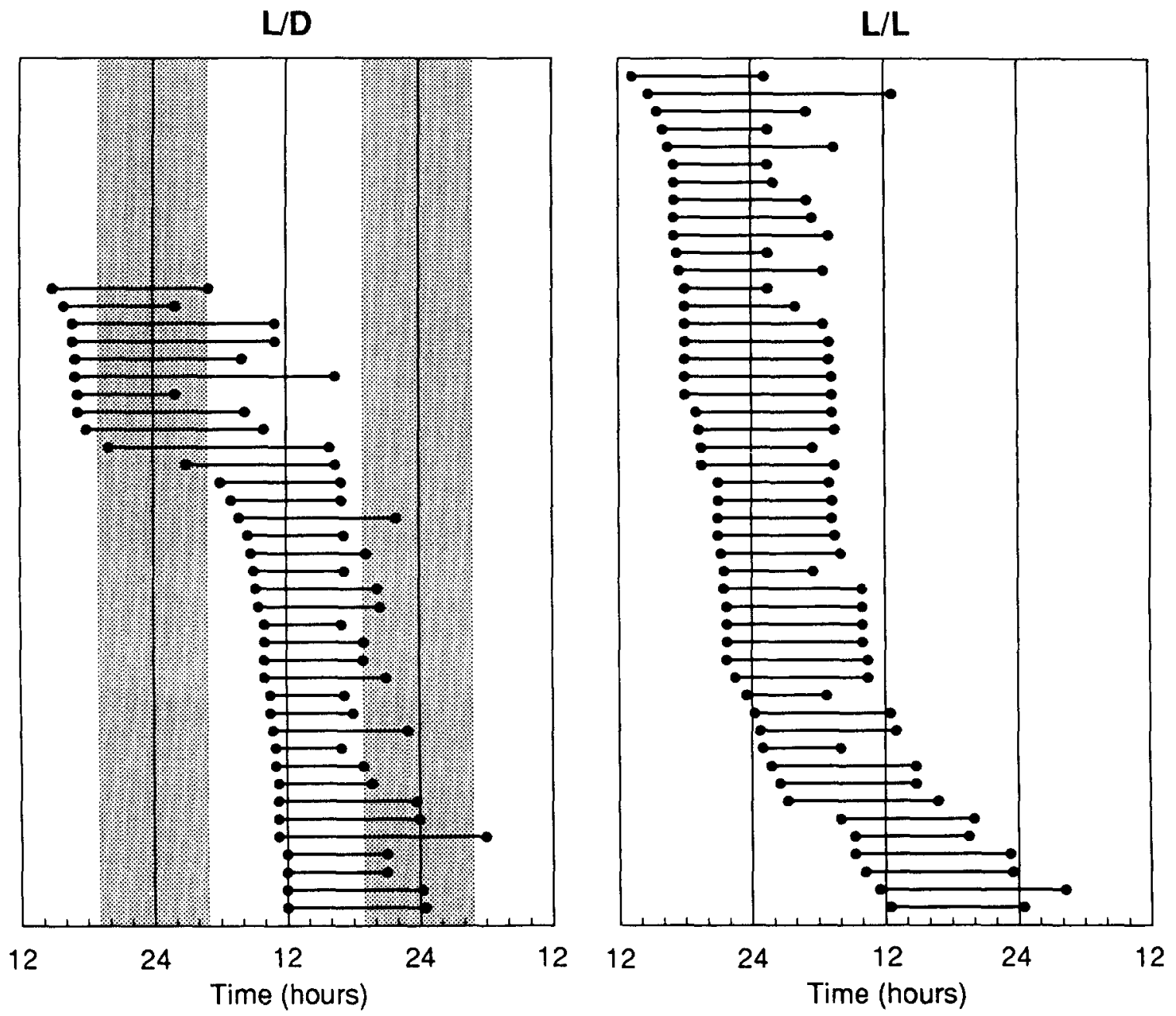

FIG. 2. Parturition-to-postpartum estrus interval for all LD and LL births. Shaded area represents lights off.

the Mann-Whitney and Wilcoxon tests were used to analyze differences on this variable. No differences were found across the first and second births $(p>.10)$ or across the LD and LL groups $(p>.10$ ) (Table 2, Fig. 1,2). However, both visual inspection of Fig. 2 and $F_{\max }$ indicate that the birth-estrus interval was less varied for LL females than LD females [e.g., LL SEM $=0.43$ vs. $\left.\mathrm{LD} \mathrm{SEM}=1.08 ; F_{\max }(2,23)=5.6 ; p<.01\right]$. This difference in variability, together with previous research on postpartum estrus $(2,8,15)$, suggested that the LD births followed two distinct patterns. The first pattern $(n=26)$ was characterized by birth early in the day (before 1200) with estrous behavior occurring within $7-13 \mathrm{~h}(\overline{\mathrm{x}}=9.88 \mathrm{~h}$, range $=6.5-19.5)$; the second pattern $(n=10)$ was characterized by birth later in the day (after 1400 ) with estrous typically occurring $10-20 \mathrm{~h}$ later $(\overline{\mathrm{x}}=15.45$ $h$, range $=8.5-23.5$ ). The parturition-to-estrus interval for these early and late birth patterns was statistically compared, ${ }^{2}$ with the resultant difference being significant $[t(31)=4.22 ; p<.001$ ).
Successful impregnations and litter viability (Table 3). There was no difference in the proportion of litters carried to term when tested across the two pregnancies resulting from postpartum estrus $(z=.99 ; p>.05)$. There was also no difference across groups (LL vs. LD) on this measure $(z=1.04 ; p>.05$ ). In addition, there were no main effects (GROUP or BIRTH) for differences in number of live births, litter size, or pup weights across births or groups ( $p \geq .572$ for all comparisons). There were, however, GROUP $\times$ BIRTH interactions on both litter size and pup weights [littersize: $F(2,54)=4.86 ; p=.011$; weight: $F(2,54)=3.43 ; p=.048)$. Post hoc analysis revealed that litter size was larger for the LD group (vs. LL) on the third birth $(p<$ .05 ), but pup weight was also lower for the LD group on this birth $(p<.05)$.

Number of females ovulating spontaneously. Following the third parturition, ovaries were inspected under magnification for the presence of corpora lutea originating from postpartum ovu-

\footnotetext{
${ }^{2}$ Because the correlation for the parturition-to-postpartum estrus interval between first and second births was low $(r=-.05 ; p=.86)$ for individual females, data were treated as independent observations and compared with an independent $t$-test.
} 
TABLE 2

POSTPARTUM ESTRUS AND OVULATION UNDER LD OR L.L CONDITION

\begin{tabular}{clcc}
\hline Birth & & LL & LD \\
\hline \multirow{2}{*}{1} & $n$ giving birth & 26 & 23 \\
& \% showing pp estrus & 100 & 96 \\
& parturition-estrus interval & $11.27 \mathrm{~h}$ & $11.25 \mathrm{~h}$ \\
& (x \pm standard error) & $(0.43)$ & $(1.08)$ \\
2 & $n$ giving birth & 22 & 14 \\
& \% showing pp estrus & 100 & 100 \\
& parturition-estrus interval & $11.78 \mathrm{~h}$ & $13.00 \mathrm{~h}$ \\
& (x \pm standard error) & $(0.46)$ & $(0.74)$ \\
3 & $n$ giving birth & 19 & 12 \\
& $n$ (\%) showing corpora lutea & $13 / 18$ & $8 / 8$ \\
& & $(72)$ & $(100)$ \\
\hline
\end{tabular}

lation. The presence of such structures would be an indication of spontaneous ovulation. In the LL group, corpora lutea were found in 13 of $18(72 \%)$ females inspected. In LD females, all that were inspected ( 8 out of 8 ) were found to have corpora lutea. This difference was not significant $(z=1.67 ; p>.05)$.

\section{DISCUSSION}

The results of this study confirm well-known findings regarding the influence of LD cyclicity on the time of parturition and postpartum estrus. Specifically, parturition is clearly inhibited by darkness (or, more precisely, the circadian mechanism entrained to the LD cycle) (22), constant light disrupts the normal $24 \mathrm{~h}$ pattern of birthing $(3,4,26)$, and postpartum estrus is typically delayed by $10-20 \mathrm{~h}$ when birth occurs late in the light phase of the photoperiod $(8,15)$. However, two new conclusions may be reached on the basis of these data. (i) An LD cycle is not necessary for estrus or spontaneous ovulation in the postpartum female as it is in the normally cycling female (27). (ii) Long-term exposure to constant light has no disruptive effect on estrous behavior, fertility, and pup viability in the postpartum female, as it does in the cycling female $(5,6,12)$.

Regarding the first conclusion, it appears that circadian mechanisms regulated by LD cyclicity exert no effect on whether or not postpartum estrus and ovulation will occur. During the postpartum period, females in both LL and LD groups were receptive, as indicated by behavioral tests, and ovulated, as indicated by successful gestations. And despite long term exposure to constant light, most ovulations occurring in the LL group during the postpartum period were spontaneous. This pattern contrasts sharply with that of the normally cycling female where LD stimulation is essential to maintain the LH surge and spontaneous ovulation $(6,32)$. Although it is possible that other (non-photic) circadian stimuli or the endogenous circadian clock trigger ovulation and estrus in the postpartum female, such nonphotically driven clocks are not adequate to maintain ovulation and cyclicity in the LLinduced constant estrus female.

Females maintained under constant light displayed fairly consistent intervals between birth and estrus, whereas females maintained under the LD cycle showed substantial variation in this interval. This higher variation in LD females resulted from the extended birth-to-estrus interval observed in animals delivering shortly before darkness. This finding suggests that the primary role of $L D$ rhythms in the postpartum rat is that of fine-tuning the timing of the inevitable events of postpartum estrus and ovulation. That is, since these events occur reliably in the absence of an LD cycle, the actual trigger for the LH surge, ovulation and estrous behavior apparently does not depend on LD stimulation.

One suggested trigger for postpartum ovulation and estrus is the parturitional process itself (11). That is, unlike the cycling female where the LH surge and ovulation rely on LD cyclicity, postpartum fertility may depend more upon events surrounding or stimulated by the labor process. If events embedded in the parturitional process are sufficient for triggering postpartum estrus, how then might a late afternoon birth delay this event? Previous models suggest that circadian mechanisms "allow" the estrus to occur by acting as a gating mechanism. Our data, along with others, indicate that the period of impending darkness represents a closed gate, whereas the recent onset of light represents an open gate. The endocrinological events underlying this interactive model, however, are more difficult to ascertain.Estrous behavior occurs in response to ovarian hormones, namely long term exposure ( $12-48 \mathrm{~h}$ ) to estrogen, and a short term rise in progesterone. Estrogen levels in the rat are known to rise significantly before birth $(23,28,34)$ to about $40-70 \%$ of the levels normally found in the cycling estrous female. The latency between the release of estrogen around parturition and its neural activation of estrous behavior may define the typical interval between birth and postpartum heat. However, if the events for postpartum estrus and ovulation are set in motion around the time of parturition (e.g., through estrogen release or cervical stimulation), to account for the delay in estrus seen in females giving birth in the late afternoon, there is need for a mechanism that can postpone the stimulatory action of this hormone with respect to the onset of receptivity. Such postponement may be effected through the delay of progesterone release, the result of dark-induced inhibition of the preovulatory LH surge. Yet estrogen by itself is capable of inducing receptivity in ovariectomized rats (10) and unpublished observations (van der Schoot \& Rowland) suggest that the postpartum LH surge (see 29) and progesterone rise are not necessary for postpartum estrus. Therefore, a mechanism capable of postponing the activating effect of estrogen, already present in the system at parturition, on estrous behavior remains to be elucidated. It may be that the estrogen release associated with late afternoon births occurs in the morning or midday, thereby postponing attainment of a behavioral threshold. For example, when estrogen is administered to ovariectomized rats at morning or midday $(16,17)$, behavioral sensitivity (tested $48 \mathrm{~h}$ later) is lower than when administered during the onset or middle of the night. Perhaps a similar circadian mechanism-one which effects

TABLE 3

COMPARISON OF LL AND LD CONDITION ON IMPREGNATION AND LITTER VIABILITY OVER THREE SUCCESSIVE PREGNANCIES

\begin{tabular}{clcc}
\hline Birth & & LL & LD \\
\hline 1 & No. impregnated & 26 & 23 \\
& \% pup mortality & 0.0 & 0.0 \\
& mean littersize & 9.7 & 10.7 \\
& mean pup weight & 5.5 & 5.7 \\
2 & impregnated & 26 & 22 \\
& \% successful pregnancy & 84 & 61 \\
& \% pup mortality & 0.0 & 3.0 \\
& mean littersize & 10.2 & 9.4 \\
& mean pup weight & 5.8 & 6.1 \\
3 & no. impregnated & 22 & 14 \\
& \% successful pregnancy & 86 & 86 \\
& \% pup mortality & 1.0 & 1.0 \\
& mean littersize & 8.2 & 11.2 \\
& mean pup weight & 6.4 & 5.9 \\
& & & \\
\end{tabular}


changes in sensitivity to estrogen-is operative in the postpartum rat, such that the onset of estrous behavior is delayed when endogenous estrogen first becomes available at morning or midday.

A second conclusion drawn from this study is that constant light does not disrupt overall fertility or litter viability in the lactating and/or pregnant female. Such findings are in marked contrast with the effects of constant light on the fertility of the female that regresses to a state of constant estrus. Specifically, in females exposed to only two weeks of constant light, blastocyst implantation following mating is sharply reduced (21). Estrous cyclicity has been shown to decrease greatly within as little as 24-30 days of constant light (e.g., 9,18); and data from our own lab with 25 cycling females indicates that by 55 days of constant light exposure, $96 \%$ had ceased to cycle (van der Schoot, unpublished observations). Moreover, the incidence of pregnancy resulting from matings during light-induced constant estrus, and the viability of offspring from such matings, is very low compared with normally cycling females $(5,6)$. In sharp contrast with these effects, constant light in our experiment had no adverse effect on estrous behavior after 12 and 40 days of exposure, and no significant effect on ovulation (and presumably estrous behavior as well) after 60 days of exposure. Furthermore, no deleterious effect was seen on offspring viability from postpartum matings after 12 or 40 days of exposure to constant light.

In conclusion, the fact that postpartum estrous behavior, ovulation, implantation, and high litter viability all occurred reliably in females under constant light suggests that the extent to which LD cyclicity influences fertility may differ greatly in the cycling vs. immediate postpartum rat. In the cycling rat, the LD cycle may occupy a more regulatory (central) role with respect to reproduction, whereas in the postpartum-estrus rat, the LD cycle appears to play a fine-tuning role. Interestingly, the strong resistance of the postpartum-pregnant rat to the anti-fertility effects of constant light suggests that such females could provide a useful model for future studies investigating constant light effects in animals that need to be impregnated for research or experimental purposes.

\section{ACKNOWLEDGEMENTS}

We gratefully acknowledge the contributions of Jan van Ophemert, Henk van der Heyden, and Els J. Houtsmuller.

\section{REFERENCES}

1. Adams, C. E. Prenatal mortality in the rabbit oryctolagus cuniculus. J. Reprod. Fertil. 1:36-44; 1960.

2. Blandau, R. J.; Soderwall, A. L. Postparturitional heat and the time of ovulation in the albino rat. Data on parturition. Anat. Rec. $81: 419-429 ; 1941$.

3. Bosc, M. J. Time of parturition in rats after melatonin administration or change of photoperiod. J. Reprod. Fertil. 80:563-568; 1987

4. Bosc, M. J.; Nicolle, A. Influence of photoperiod on the time of parturition in the rat I. Effect of length of daily illumination on normal or adrenalectomized animals. Reprod. Nutr. Dev. 20, 735$745 ; 1980$.

5. Brown-Grant, $K$. The induction of pseudopregnancy and pregnancy by mating in albino rats exposed to constant light. Horm. Behav $8: 62-76 ; 1977$

6. Brown-Grant, K.; Davidson, J. M.; Greig, F. Induced ovulation in albino rats exposed to constant light. J. Endocrinol. 57:7-23; 1973.

7. Bruning, J. L.; Kintz, B. L. Computational handbook of statistics Glenview, Il: Scott, Foresman and Co.; 1977.

8. Connor, J. R.; Davis, H. N. Postpartum estrus in Norway rats. I. Behav. Biol. Reprod. 23:994-999; 1980.

9. Daane, T. A.; Parlow, A. F. Serus FSH and LH in constant lightinduced persistent estrus:short-term and long-term studies. Endocrinology 88:964-968; 1971.

10. de Jonge, F. H.; Burger, J.; van de Poll, N. E. Acute effects of gonadal hormones on lordosis behavior of the female rat. Behav. Brain Res. 20:57-62; 1986.

11. Everett, J. W.; Sayer, C. H.; Markee, J. E. A neurogenic timing factor in control of the ovulatory discharge of luteinizing hormone in the cyclic rat. Endocrinology 44:234-250; 1949.

12. Everett, J. W.; Tejasen, T. The time factor in ovulation blockade in rats under differing lighting conditions. Endocrinology 80:790-792; 1967.

13. Flint, A. P.; Heap, R. P.; Ingram, D. L.; Walters, D. E. The effect of daylength on the duration of pregnancy and the onset of parturition in the rat. Quart. J. Exp. Physiol. 71:285-293; 1986.

14. Fox, S. R.; Smith, M. S. Postpartum preovulatory surge of gonadtropin secretion in the rat may be initiated by the labor process. Biol. Reprod. 31:619-626; 1984.

15. Gilbert, A. N.; Rosenwasser, A. M.; Adler, N. T. Timing of parturition and postpartum mating in Norway rats: Interaction of an interval timer and a circadian gate. Physiol. Behav. 34(1):61-63; 1985.

16. Hansen, S.; Sodersten, P.; Srebro, B. A daily rhythm in the behavioral sensitivity of the female rat to oestradiol. J. Endocrinol. 77:381-388; 1978 .

17. Hansen, S.; Sodersten, P.; Eneroth, P.; Srebro, B. A sexually dimorphic rhythm in oestradiol-activated lordosis behavior in the rat. J. Endocrinol. 83:267-274; 1979.
18. Hardy, D. F. The effect of constant light on the estrous cycle and behavior of the female rat. Physiol. Behav. 5:421-425; 1970.

19. Hoffman, J. C.; Schwartz, N. B. Timing of postpartum ovulation in the rat. Endocrinology 76:620-625; 1965.

20. Kuehn, R. E.; Beach, F. A. Quantitative measurement of sexual receptivity in female rats. Behavior 21:282-299; 1963.

21. Lilit, N.; Yeager, V. L. Effect on photoperiod on time of blastocyst implantation in the rat. Proc. Exp. Biol. Med. 145:894-896; 1974.

22. Lincoln, D. W.; Porter, D. G. Timing of the photoperiod and the hour of birth in rats. Nature 260:780-781; 1976.

23. Lincoln, D. W.; Porter, D. G. Photoperiodic dissection of endocrine events at parturition. Anim. Reprod. Sci. 2:97-115; 1979.

24. Mitchell, J. A.; Yochim, J. M. Influence of environmental lighting on duration of pregnancy in the rat. Endocrinology 87:472-480;1970.

25. Plaut, S. M.; Grota, L. J.; Ader, R.; Graham, R. C III. Effects of handling and the light-dark cycle on the time of parturition in the rat. Lab. Anim. Care 20:447-453.

26. Rowland, D. L.; Dykstra, T.; Wagonblast, A. Timing of parturition in the rat:an analysis of successive births. Chronobiologia 18(1):31-38; 1991.

27. Schwartz, N. B. A model for regulation of ovulation in the rat. Recent Prog. Horm. Res. 25:1-55; 1969.

28. Shaikh, A. A. Estrone and estradiol levels in the ovarian venous blood from rats during the estrous cycle and pregnancy. Biol. Reprod. 5:297-307; 1971.

29. van der Schoot, P. Preovulatory requirements of ovarian hormones for the production of the ovulatory luteinizing hormone surge in 4 and 5 day cycles of female rats. J. Endocrinol. 80:29P-30P; 1979.

30. van der Schoot, P.; van Ophemert, J.; Baumgarten. R. Copulatory stimuli in rats induce heat abbreviation through effects on genitalia but not through effects on central nervous mechanisms supporting the steroid hormone-induced sexual responsiveness. Behav. Brain Res. 49:213-223; 1992.

31. van Riemsdyk, A.; Zeilmaker, G. H. Ovulation blockade and receptivity in the cyclic rat. Acta Endocrinol. (Kbh) 90:711-717; 1979.

32. Watts, A. G.; Fink, G. Effects of progesterone on the pituitary responsiveness to, and priming effect of luteinizing hormone releasing hormone in female rats exposed to constant light. Neuroendocrinology $40: 152-159 ; 1985$.

33. Ying, S.; Gove, S.; Fang, V. F.; Greep, R. O. Ovulation in the postpartum rat. Endocrinology 92:108-116; 1973.

34. Yoshinaga, K.; Hawkins, R. A.; Stocker, J. F. Estrogen secretion by the rat ovary in vivo during the estrous cycle and pregnancy. Endocrinology 85:103-113; 1969,

35. Zeilmaker, G. H. Quantitative studies on the effect of the suckling stimulus on blastocyst implantation in the rat. Acta Endocrinol. 46:483-492; 1964. 